\section{A CASE OF CONJOINED TWINS}

NTINOS C. MYRIANTHOPOULOS, BRIGITTE DE LA BURDE

National Institute of Neurological Diseases and Stroke, NIH, Bethesda, Maryland, USA

Medical College of Virginia, Richmond, Virginia, USA

Among 56,249 maternities in the Collaborative Perinatal Project, 6I 5 were twin maternities. One of these resulted in stillborn thoraco-omphalopagus female twins with multiple cardiovascular, alimentary, and other malformations. The case is of further interest in that the mother had a surgically removed brain tumor in childhood and exhibited neurological symptoms and bizarre behavior before and during pregnancy. Drugs and treatments which she received during pregnancy are not known to be teratogenic.

Ntinos C. Myrianthopoulos, NINDS, NIH, Bethesda, Maryland 20014, USA

\section{MONOAMNIOTIC TWINS}

\section{RAGNA FOGLMANN}

Department of Obstetrics, St. Foseph Hospital, Copenhagen, Denmark

Department of Obstetrics, Frederiksberg Hospital, Copenhagen, Denmark

Monoamniotic twin pregnancy is a rare condition, which occurs when the twins are contained in a single sac.

Six new cases of monoamniotic twins, born at the Departments of Obstetrics of St. Josephs and Frederiksberg Hospitals, are reported. All had true knots of the cords, the result being double survival in five cases and eleven normal children.

The mechanism of twin development is described and monoamniotic twins are placed in accordance with the two theories from the literature.

A short review of both the Scandinavian and the world cases is presented.

In one of the new cases, we have a clearly dividing plica, possibly caused by a spontaneous or traumatic disruption of a previous diamniotic membrane; however, genetic examinations showed truly identical boys.

Dr. Ragna Foglmann, Kattesundet 2/2 DK-1458, Copenhagen, Denmark
FAMILIAL TWINNING: A POSSIBLE EXAMPLE OF SUPERFETATION IN MAN

\author{
S. A. RHINE, W. E. NANGE, J. R. MELIN, \\ C. E. SKIDMORE
}

Department of Medical Genetics, Indiana University School of Medicine, Indianapolis, Indiana, USA

Studies of individual families and interracial crosses have generally suggested that sex-limited genetic factors in the mother influence the frequency of $\mathrm{DZ}$ twinning. However we have observed a family, shown below, in which the tendency to bear twins was expressed in the offspring of males as well as females. All of the twins born in this family were also unusual because of marked discordance in birth weight and gestational age. In five of the six pairs, one twin was normal while the other was either a macerated fetal mass, stillborn, or died of prematurity in the neonatal period.

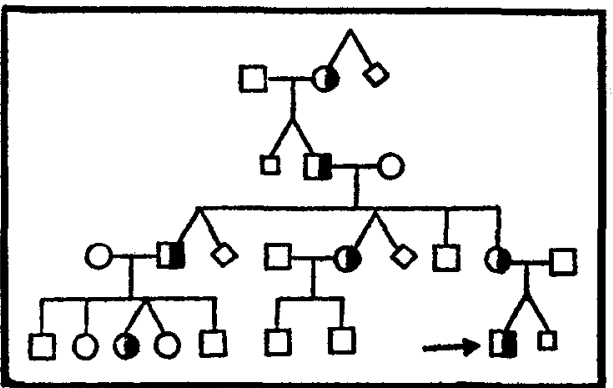

The one pair in which both twins did survive is known to be $\mathrm{DZ}$ and showed a difference in maturity and a $21 \%$ discrepancy in birth weight (230og as compared to I850g). Thus, twinning in this family appears to be transmitted as an autosomal dominant trait which is expressed in the offspring of both female and male carriers. Genetic mechanisms which could possibly explain this familial aggregation of markedly discordant twins include heritable meiotic abnormalities which lead to polar-body twinning, delayed implantation of the embryo, retarded or arrested intrauterine development, and superfetation. Of all these possibilities, superfetation seems most consistent with the genetic transmission and expression of the trait in the offspring of both males and females. Superfetation re- 
fers to the occurrence of ovulation, fertilization, and subsequent implantation, of a second conceptus during an ongoing pregnancy, leading to the generation of two fetuses of different gestational ages within the same uterus. Reports of alleged superfetation in numerous mammalian species, including man, can be found in the literature dating from antiquity. The evidence usually cited in human cases includes the separate delivery, to the same mother, of full-term infants more than 30 days apart, or the birth or abortion of twin infants that are different in birth weight and developmental age. In addition, many reports of dichorial fetus papyraceus in man could also represent superfetation, although the accepted explanation has usually been arrested intrauterine growth. Even though these examples in the literature are numerous, no reference has been found which hypothesizes a physiological mechanism for explaining superfetation.

The most plausible explanation of the pedigree is that a dominantly inherited gene is segregating in the family which is expressed in the fetal placenta where it acts to reverse the normal hormonal inhibition of ovulation. The mutant gene could affect the structure or function of chorionic gonadotropin, the placental steroid sulfatases, or some other placental gene product that is involved in hormone synthesis. Since both the father and the mother contribute to the genotype of the placenta, superfetation could occur among the offspring of both males and females who carry the gene. However, even if a second ovulation did occur, superfetation would be observed only in the event of fertilization and successful implantation.

The frequency of superfetation in man is unknown. It is possible that the so called "father factor" identified in early studies of the inheritance of $\mathrm{DZ}$ twinning may be explained by superfetation. If an appreciable proportion of $\mathrm{DZ}$ twins can be shown to arise by this mechanism, it would have important implications for twin studies since it would identify a previously unrecognized source of variation in $\mathrm{DZ}$ twins. In addition, the origin of dichorial fetus papyraceus and racial differences in the incidence of $\mathrm{DZ}$ twinning should be reevaluated with this possibility in mind.

Dr. Walter E. Nance, Department of Medical Genetics, I too West Michigan Street, Indianapolis, Indiana 46202 , USA

\section{HEREDITY OF TWINNING IN FAMILIES OF MZ TWINS}

\author{
L. GEDDA, O. RUSSO, M. CAPONE
}

The Gregor Mendel Institute of Medical Genetics and Twin Research, Rome, Italy

Whereas the existence of some genetic factor underlying the phenomenon of twinning is almost generally accepted with respect to $\mathrm{DZ}$ twins, no such agreement exists with respect to $M Z$ twins.

The possible existence of genetic factors underlying $\mathrm{MZ}$ twinning has been verified through an analysis of segregation in the sibships of $\mathrm{MZ}$ twins and in those of their parents, carried out on a sample of $60 \mathrm{MZ}$ twin pairs ( $30 \mathrm{M}$ and $30 \mathrm{~F}$ ).

Haldane's a priori method has been applied, considering the sample as obtained through a complete and through an incomplete ascertainment.

The results may lead to cautiously confirm the hypothesis of some genetic conditioning of $\mathrm{MZ}$ twinning.

Prof. Luigi Gedda, Istituto Mendel, Piazza Galeno 5, oor6i Roma, Italy

\section{THE STUDY \\ OF MULTIPLE-BIRTH FACTORS IN THE FAMILIES OF TWINS}

\author{
R. P. MARTYNOVA, E. T. LILLYN
}

Institute of Cytology and Genetics, Siberian Branch of the Academy of Sciences, Novosibirsk, USSR

Institute of Medical Genetics, Medical Academy of Sciences, Moscow, USSR

The study of the influence of hereditary and paratypic multiple-birth factors on the birth, in a given family, of $M Z$ or $D Z$ twins, has hitherto been relatively little considered.

Using multifactorial correlation and regression analyses, questionnaires of parents of $86 \mathrm{MZ}$ and $173 \mathrm{DZ}$ pairs, filled out through personal interviews, were analyzed by means of a computer. The questionnaire included 26 questions. The evaluation of the regression coefficient resulted in the establishment of six factors influencing the birth of $\mathrm{MZ}$ or DZ twins, and the study of the correla- 